\title{
Assessing the long-term ecological sustainability of dambo cultivation in southern Africa: ten-year case studies from Zambia and Malawi
}

\author{
Donovan C. Kotze ${ }^{1 *}$ and Adrian P. Wood ${ }^{2}$
}

${ }^{1}$ Centre for Water Resources Research, University of KwaZulu-Natal, South Africa, kotzed@ukzn.ac.za

${ }^{2}$ Sustainable and Resilient Communities Group, SURGE, Business School, University of Huddersfield, UK

*corresponding author

\begin{abstract}
Internationally, evidence-based assessments of the sustainability of cultivation in seasonal wetlands are lacking despite such areas, including dambos in southern Africa, providing key areas for cultivation. The Striking a Balance project, which supported multiple use, including cultivation, of dambos, was undertaken in Zambia and Malawi between 2006 and 2008. Using the baseline WET-SustainableUse assessments made in 2008 in four of these dambos, the procedures were repeated in 2019 to explore the ecological sustainability of current use based on the concept of Thresholds of Potential Concern (TPC). This concept was applied to the five components of ecological health, namely hydrology, geomorphology, soil organic matter, nutrient retention and vegetation composition. In all four dambos, despite ten years of multiple use including cultivation, the change in ecological health between 2008 and 2019 was generally small, and overall, the ecological health of the four dambos has largely been maintained. However, there are some concerns, particularly with respect to vegetation composition, which had fallen below the TPC for two of the dambos. The methods used and the findings appear to have wider
\end{abstract}


application in Africa for long-term monitoring the ecological health of seasonal wetlands and determining the ecological bounds for wetland cultivation.

Key words: cultivation, dambo, ecological health, sustainability, wetland

\section{Introduction}

The FAO-led project "Guidelines on Agriculture, Wetlands and Water Resource Interactions" highlights the need to: (1) identify the ecological bounds for different provisioning services and (2) maximize production in a sustainable manner (Wood and van Halsema 2008). Specifically, there is a need to assess the trade-off between wetland crop production and sustaining wetland ecological condition and ecosystem services supply (health) (McCartney et al. 2005; Wood and van Halsema 2008). However, as yet, little evidence-based information exists with respect to such trade-offs (Wood and van Halsema 2008). The need for assessing these trade-offs is imperative in dambos, which are seasonally waterlogged wetlands at the head of valleys, as dambos are increasingly used for cultivation and natural resource provision across Africa's tropical savannas (Rebelo et al. 2010). The direct use of dambos by subsistence farmers has traditionally played a critical role in the livelihoods of local populations (Acres et al. 1985) and researchers such as Trapnell (1953) have long recognized the underutilized potential that dambos have for supporting cultivation. However, direct use may potentially degrade dambos, which is often to the detriment of both local users and society at large (Whitlow 1989) and Nyamadzawo et al. (2015) and Musasa and Marambanyika (2020) highlight the specific need for further research to evaluate the environmental sustainability of dambo cultivation. More broadly, the Second Warning to Humanity 
identifies the imperative to inform the development of appropriate policy responses at national and international levels to ensure the ongoing sustainable use of wetlands (Finlayson 2019) in the face of their continuing loss, both globally and in Africa (Davidson 2014 and Dixon et al. 2016). A 31\% decline in inland wetlands from 1970 to 2008 is reported for Africa (Dixon et al. 2016) and in Zimbabwe, where, like Malawi and Zambia, the wetlands are predominantly dambos used by small scale farmers, $57 \%$ of the wetlands are moderately degraded and 27\% are severely degraded (Musasa and Marambanyika 2020). Furthermore, the trajectory of ecological condition suggests that if sustainable use interventions are not implemented and enforced, more than half of the moderately degraded wetlands will become severely degraded (Musasa and Marambanyika 2020).

While several assessments of the cultivation of African wetlands have been undertaken (e.g. Kotze 2011; Marambanyika et al. 2016) these tend to be "snap-shots" in time, and repeat assessments to provide a longer-term perspective are lacking. Thus, an attempt was made to achieve such a longer-term perspective at two wetlands in Mpika District of Zambia and two wetlands in Kasungu District of Malawi. These four wetlands formed part of the Striking a Balance (SAB) project undertaken by Wetland Action and Self Help Africa, along with local partners between 2006 and 2008 in two areas of southern Africa where dambo cultivation was increasing (Ndiyoi, 2009). The project aimed to encourage sustainable dambo management to help reduce poverty, improve food security and maintain environmental functioning and biodiversity, by applying the Functional Landscape Approach (FLA) which promotes sustainable land management practices in a linked unit comprising catchments and dambos, and with local institutions (and by-laws) developed for managing these areas together (Wood 2008; Wood and Thawe 2013).

Baseline WET-SustainableUse assessments in May/June 2008 at these four dambos were repeated in July 2019. The primary purpose of this study was to describe how the current 2019 ecological health of these 
wetlands compares with the 2008 baseline assessment, after 10 years of multiple use of dambos, including cultivation as the primary use in all four of the dambos. Based on these results and the land-use context of the dambos, the study also assessed the ecological sustainability of use, which contributed to an assessment of the long-term impacts of the SAB project.

Sustainability encompasses both an environmental and social dimension. Thus, the above investigation of ecological sustainability was complimented by an investigation of the social sustainability of the use of the four dambos, based on focus group discussions at each of the four dambos and drawing on existing investigations such as that of Dixon and Carrie (2015) and Mbewe and Sampa (2018). However, the findings of the social sustainability assessment are largely outside the scope of this paper and are reported more fully in the overall integrated sustainability assessment of Kotze and Wood (2019).

\section{Methods}

The assessment of current ecological health/condition is based on field assessments conducted in July 2019. This was after what farmers reported as a good rainfall season in both countries which had produced above their average upland crops. This was compared against the baseline assessments for the Simlemba dambos in Malawi (Kotze et al. 2008) and the Mpika dambos in Zambia (Sampa 2008; Nyirenda 2008; Kotze 2009). WET-SustainableUse (Kotze 2010) was the primary method used to carry out the assessment of wetland ecological health on both occasions. WET-SustainableUse (Kotze 2010) is a modular approach for assessing the present ecological condition of wetlands based on WET-Health (Macfarlane et al. 2009). WET-SustainableUse assists in identifying the likely contribution of specific uses, such as cultivation, to five components of ecological health, namely hydrology, geomorphology (erosion/sediment trapping), Soil Organic Matter (SOM), nutrient cycling, and vegetation composition 
(2010; 2011). Although the five components are assessed separately, it is acknowledged that they are closely interlinked.

For each of the five components, the impacts of human activities on ecological condition were scored based on readily observed indicators/factors (e.g. artificial drainage channel depth and orientation) which are outlined in Supplementary Tables S1 to S4. This scoring requires both a quantitative perspective and qualitative assessment skills on the part of the assessor. In order to promote consistency of assessment, D Kotze, who is experienced in the application of the method, carried out all of the baseline (2008) and follow-up assessments (2019).

For each of the individual components of wetland health, the spatial extent of the impact of individual activities was assessed and then the intensity of impact of each activity in the affected area was assessed based on a scale of 0 (no impact) to 10 (critical impact) (Table 1). The extent and intensity were then combined to determine an overall magnitude of impact for each component of wetland health, also on a scale of 0 to 10, as follows: Magnitude $=$ Extent $/ 100$ x Intensity. For example: if a given activity was affecting $50 \%$ of the dambo and its intensity was 6 on one component then the magnitude of the impact is $50 / 100 \times 6=3$ for that component. Ecological health, scored on a scale of 0 (critical) to 10 (pristine) is inversely related to the impact score and is determined by subtracting the sum of the impact magnitude scores from 10. If the activity in the above example was the only activity impacting on the dambo then the ecological health of the dambo would be $10-3=7$ for that component, which according to Table 1 would fall into a $\mathrm{C}$ health category.

When assessing the impact of catchment activities on the quantity and timing of water inputs to the dambo a visual estimate was made using GoogleEarth images of the approximate extent of different land-cover types in the upstream catchment of each dambo. These estimates were verified during the field surveys 
carried out in 2008 and 2019. Within the wetland, the extent of cultivation was mapped from GoogleEarth images where available, and verified during the field assessments. Verification was undertaken during the course of the transect walks in order to determine if the land-cover types had been correctly assigned and if adjustments to the land-cover unit boundaries were required. The location of key boundary points were recorded with a Garmin GPS 60.

WET-SustainableUse does not prescribe what is considered sustainable or not. Instead it recommends Thresholds of Potential Concern (TPCs) for each of the four components of ecological health, with each TPC referring to a threshold along a continuum of environmental change which is specific to the particular management context (Rogers and Biggs 1999; Kotze 2010). The TPCs recommended by Kotze (2010) were used, taking into account that the primary management objective for all four dambos was sustaining livelihoods primarily through dambo cultivation. For this, the TPCs for the sediment retention, SOM accumulation and nutrient cycling components were set reasonably high (because of their critical contribution to cultivation) and the TPC for the vegetation component was set lower (because minimally impacted vegetation is not specifically required to meet the livelihood objective). If biodiversity conservation had been the primary management context/goal then the TPC for all components including the vegetation would be set high.

The field assessment in 2019 was conducted in one and half days at each site, comprising a transect walk through the length of the wetland by the two researchers accompanied by a local consultant and a Self Help Africa staff member along with two or three knowledgeable local farmers. This allowed for direct observations to be made of indicators of dambo ecological condition and sustainability of use employed in the WET-SustainableUse assessment. It also provided the opportunity to speak to local dambo users encountered in the field concerning their views of the sustainability of present use. Further discussions 
were held in a village meeting of between 14 and 30 local people convened in 2019 at each of the four dambos.

\section{The study sites}

Six dambos, which had been assessed in 2008, were considered for re-assessment in 2019. However, the time available in 2019 allowed for the assessment of only four of these. The four dambos were selected in order to represent a range of biophysical features, levels of use and catchment contexts (Table 2). In

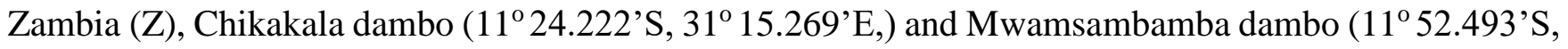
$\left.31^{\circ} 29.979^{\prime} E\right)$ are located near Mpika town in the catchment of the Chambeshi River, which feeds Lake Bangweulu (Figure 1). In Malawi (M), Katema dambo (12 $43.368^{\circ}$ S, $33^{\circ} 35.940$ 'E) and Chiotha dambo $\left(12^{\circ} 46.697^{\prime} \mathrm{S}, 33^{\circ} 40.390^{\prime} \mathrm{E}\right)$ are located north of Kasungu town in the drainage basin of the Dwangwa River (Figure 1), which flows into Lake Malawi, an aquatic system of regional and global importance (Thieme et al. 2005). Although the mean annual precipitation is higher in the sites in Zambia compared to Malawi ( 1100 mm compared with $\sim 800 \mathrm{~mm})$, all sites have an extended dry season from May to September / November.

The four wetland sites have varying populations who use them, in some cases single villages and in others multiple villages. The number of households using the wetland areas vary from 26 and 50 in Katema and Chiotha, to 131 and 328 in Malawila and Chikakala (Mbewe, 2007; Msukwa, 2007; McElwee and Wood, 2017). These wetland farming households are between $40 \%$ and $70 \%$ of the total village household populations and these numbers are similar to those using the wetlands after the SAB project (2008). Wetland farming is very much a seasonal supplement to upland farming, which is dominated by maize, but includes finger millet and sorghum in Zambia and Malawi respectively. Livestock are only a limited feature of the rural economy in any of the sites, and cash crop sales are limited to wetland produce and 
some upland crop such as maize and beans. Community self-assessment suggest that between $40 \%$ and $55 \%$ of the households are not food self-sufficient and have to supplement their farming through paid work or trading activities (Mbewe, 2007; Msukwa, 2007).

The relationship between the dambo and its catchment varies amongst the four dambos (Table 2). The Katema (M) and Chikakala (Z) dambos are located at the head of their valleys and occupy a large proportion of their respective upstream catchments $-13 \%$ and $14 \%$ respectively. Given that the upstream catchments of both are very gently sloped $(\sim 3 \%)$ and with sandy soils having a high infiltration capacity, there is naturally very little surface runoff from the upstream catchment into the dambo. Therefore, the primary sources of water maintaining these two dambos are direct precipitation onto the dambo and subsurface flows into the dambo as hillslope seepage. Based on the existing dambo hydrology study of McCartney and Neal (1999) and those reported by von der Heyden (2004), the sub-surface inputs are likely to include both relatively shallow interflow as well as possibly also deeper groundwater inputs, but confirmation of this would require a detailed investigation beyond the scope of this rapid assessment study.

The Mwansabamba dambo $(\mathrm{Z})$ is located somewhat lower in the valley than the Katema $(\mathrm{M})$ and Chikakala (Z) dambos, and is supplied by a much larger catchment (Table 2). Thus, relative to the size of the dambo, there is a larger upstream area potentially able to deliver water to the dambo. The soils in the catchment are predominantly sandy, which promotes infiltration and the sub-surface supply of water to the dambo, and extensive evidence can be seen of lateral seepage into the wetland. However, it is also supplied by an inflowing stream fed by the dambo's upstream catchment. The Chiotha (M) dambo occupies by far the smallest proportion of its upstream catchment (Table 2). The soils in the Chiotha catchment are relatively sandy, but appear to generally have higher clay content than the other three wetlands. There is much less evidence of seepage in the hillslopes feeding the Chiotha dambo than in the 
other three dambos, and the predominant inflows to the dambo are assumed to be from the upstream catchment. As a result, the Chiotha dambo probably has the greatest frequency of surface water inputs during major storm events in the wet season and higher energy surface flows passing through the dambo.

In all four dambos, the margins are dominated by grasses, notably Hyparrhenia spp., while the wetter body of the wetland is dominated by sedges, including Rhyncospora spp., Fuirena spp. and Eleocharis spp., together with other hydric graminoids such as Eriocaulon and Xyris species.

Traditionally, the predominant agriculture practiced in the uplands around Chikakala and Mwamsabamba dambos in Zambia was chitemene cultivation, where the branches of trees are collected from an area of several hectares (the 'outfield'), and gathered in the 'infield', an area about 0.4 ha in size, and burnt, with the ash enhancing fertility. When the infield is exhausted after a few years of cultivation, it is abandoned and traditionally left fallow for 20 to 30 years (Strømgaard 1984). In Malawi in the Katema and Chiotha dambos, similar shifting cultivation is likely to have been carried out in the past, but now the demand for land is so high that fallow periods are much shorter, and most of the cultivation is now effectively permanent.

All four dambos have probably been used since pre-colonial times, but the extent of use increased noticeably in the last two decades. Plots for cultivation are scattered around the dambos, locations being determined by rights to land and access to water from seepage or shallow wells. The residual moisture in all dambos supports food production in the dry season and early wet season. For subsistence farmers relying on upland cultivation, the early to mid-wet season is generally the most intense 'hunger period' because most/all of the food from the previous wet season has been consumed (particularly during a drought) and the harvest is not yet ready from the current rain-fed crops (Sampa 2008; Kotze et al. 2008). Crops grown in the Chikakala and Mwansabamba dambos (Z) include pumpkin, squash, maize, tomatoes, 
onions, cabbage and beans (Sampa 2008). The main crops grown in the Katema and Chiotha dambos (M) are maize, sugarcane, rape, mustard, green beans, tomatoes, Irish potatoes, and bananas. Crops are used for direct household consumption as well as for sale (Mbewe 2007; Msukwa 2007; Sampa 2008; McElwee and Wood 2017).

In Chikakala and Mwansabamba dambos (Z), preparation of cultivated lands involves digging thin turfs, which are dried, burnt and incorporated into low ridges (Sampa, 2008). "Overall this improves nutrient availability... and can sustain three to four harvests in succession over two years without chemical fertilizers and without major water application, if a moist, seepage, site in a dambo is selected." (Sampa 2008, p. 3). At Katema and Chiotha (M), the burning of turf is not practiced, and pronounced ridges and furrows are rare, but slightly raised beds are much more common, together with depression beds in the drier areas of the dambo to facilitate watering.

In all study sites the Striking a Balance (SAB) project (2006-08) worked with the farmers to explore specific challenges they faced in using dambos for cultivation and sustaining that production. Biophysical challenges included erosion in the wetlands and limited access to water at the end of the dry season. Socio-economic challenges concerned conflicts between farmers with livestock using the dambos and those growing crops, as well as finding good markets for dambo produce or choosing marketable crops to grow. Through transects walks with farmers and regular field-based discussions, a common understanding was developed by farmers and project staff of the links between land management in the catchments and dambos and the sustainable use of these areas. This led to good practice guidance being developed which was compiled by Wetland Action into the Functional Landscape Approach (FLA) (www.wetlandaction.org/functional-landscape/). 


\section{Results and discussion}

\section{Land-cover changes in each dambo and its catchment}

Land-cover is dealt with first given its important influence over all five components of ecological health. The extent of natural vegetation in both the dambo and its catchment was noticeably higher in Chikakala and Mwansabamba (Z) than in Katema and Chiotha (M) (Table 3), this being a result of the higher population density in Malawi. In terms of trends in all four dambos, there was generally a slight to moderate decline in the natural vegetation (within all four dambos, $<13 \%$ decline) and increase in cultivated area in the dambos' catchments (Table 4). Although within Chikakala and Mwansabamba dambos there was an increase ( $1 \%$ and $4 \%$ respectively) of currently cultivated area within the dambo itself, for Katema and Chiotha, there was a decrease (3\% and 1\% respectively) (Table 3). The buffer index shown at the end of Table 4 reveals that from 2008 to 2019 there was generally a slight decline in the degree to which the dambos are surrounded by a buffer of woodland as a result of a slight shrinkage in the spatial extent of the buffer.

\section{The hydrology component of dambo health}

Chikakala and Mwansabamba dambos (Z), which still have relatively high extents of natural vegetation in the dambo and its catchment (Table 3 and 4), have higher hydrology health scores than Katema and Chiotha (M) (Figure 2). Comparing health in 2008 to 2019, there is a slight decline in all four of the dambos, but somewhat more pronounced in Mwansabamba (Figure 2), which has experienced the greatest percentage increase in cultivation of the dambo (Table 3).

All of the dambos were scored as experiencing small to moderate impacts from land-use activities in their catchments. However, this was moderated by a reasonably intact buffer around all of the dambos except for Chiotha (M), although slightly less in 2019 compared with 2008 (Table 4).

The main factors concerning the cultivated plots in the dambos which affect the intensity of impact on hydrology include: (1) depth/height of ridges/furrows; (2) orientation of ridges/furrows; and (3) water use 
typically associated with the chosen crops. In both 2008 and 2019 the cultivation in Chikakala and Mwansabamba dambos (Z) took place predominantly using the ridges and furrows described by Sampa (2008). In 2008, in Chikakala and Mwansabamba the ridges appear to have been similar in terms of height and orientation. In 2019, while the same ridges were used, in Chikakala, in response to an aboveaverage preceding wet season, there had been a slight shift in location of cultivation towards the drier margins, resulting in a slightly lowered hydrology impact intensity score (Supplementary Table S5). In Mwansabamba, farmers tended to make adjustment to the wetter conditions by increasing the height of the ridges, orientating the furrows with the direction of water flow and, in some cases, constructing additional drainage ditches. This has increased the impact intensity on the hydrology (Supplementary Table S5).

In Katema (M), the plots are not ridged and furrowed, although there are drainage furrows around some of the cultivated plots and raised beds are used in the early dry season. The main difference between 2008 and 2019, is the slightly reduced extent of current cultivation. In Chiotha (M), which is inherently the least wet dambo, most cultivation takes place without any ridges and/or furrows. Thus, the intensity of hydrological impact is lower in the Katema (M) plots than in the Chikakala and Mwansabamba (Z) plots, and even lower still in Chiotha (M) (Supplementary Table S5). However, given that the extent of current cultivation is much greater in Katema and Chiotha than Chikakala and Mwansabamba (Table 3), the magnitude of impact is greater, but is nevertheless still not serious (Supplementary Table S5).

In all four dambos, similar crops were grown in 2019 compared to 2008 and therefore little change in the intensity of impact was expected relating directly to crop water use. However, at Chiotha there was more sugarcane noted relative to annual crops in 2019 (with sugarcane comprising $~ 59 \%$ of the cultivated area) compared with 2008 (with sugarcane comprising $~ 36 \%$ of the cultivated area), resulting in a slightly 
higher intensity of impact in 2019 given the higher assumed water use of sugarcane relative to annual crops.

In Chikakala and Mwansabamba dambos (Z), once the plots are abandoned, ridges and/or furrows are generally left intact. Although becoming less pronounced over time, the draining effect persists, which is reflected in the score assigned to old abandoned plots in Supplementary Table S5. In the Malawi sites there is no apparent residual hydrological impacts from cultivation.

\section{The geomorphology component of dambo health}

In both the 2008 and the 2019 assessments, geomorphology was consistently the least impacted of the five components of ecological health across all dambos except Chiotha (M) (Figure 2). Chikaklala (Z) was minimally impacted and lacking in any erosion features, while in Mwansabamba (Z) and Katema (M), these were very localized. However, Chiotha had noticeably more extensive erosion (Table 3) and the geomorphology component of wetland health was correspondingly lower (Figure 2).

Several activities take place in the cultivated plots in the four dambos which contribute to an increased vulnerability to erosion, including: (1) a high level of soil tillage, which disrupts soil structure and destroys plant roots; (2) combustion of the soil (in the case of Chikakala and Mwansabamba (Z)) which makes the soils more friable and susceptible to erosion; (3) Diminished SOM, which reduces the physical strength of soils; (4) concentration of surface water flow; and (5) diminished soil cover. However, several factors appear to act very strongly to limit the actual erosion that has taken place in the four dambos, including: (1) cultivation takes place mainly outside those portions of the dambo that appear to be most susceptible to erosion, namely the lowest-lying areas of the dambo; (2) the time when the soils are most vulnerable ( when recently tilled) generally coincides with the dry season, when the threat of erosion from water flow is lowest, and (3) the inherent erosion hazard of the dambos is low given their gentle slopes. 
Comparing the geomorphology component in 2008 with 2019 (Figure 2) there was a slight decline in scores for Chikakala and Mwansabamba, owing primarily to the increased extent of cultivation in these dambos, but in Katema and Chiotha there was a slight improvement, linked primarily to the slight decline in cultivation extent and no increase in the extent of erosion gullies. The intensity of impact on geomorphology was relatively low, but slightly higher in Mwansabamba and Chikakala (Z) than Katema (M) (Supplementary Table S6) primarily owing to the combustion of soil and the slightly higher erosion potential of Mwansabamba. The factors limiting erosion listed above are less pronounced in Chiotha (M) than in the other three dambos, particularly the erosion potential of the wetland, which is relatively high, especially due to its longitudinal slope (1.3\%) and the size of its catchment. It is not surprising, therefore, that Chiotha had the greatest extent of erosion. Increased surface runoff (e.g. from roads in the catchment) and the limited natural buffer around the wetland may be further contributing factors. Erosion in Chiotha is present as a major headcut and gulley near the outflow of the dambo, as well as erosion eating longitudinally from wells within the dambo centre. Comparing the 2008 situation with 2019 in Chiotha, it was noted that the extent of erosion ( $8 \%$ of the dambo) had remained the same and the major erosion headcut near the outflow of the wetland had not progressed any further into the wetland. Nevertheless, it remains a key threat to the wetland, particularly as the entire area immediately upstream of the headcut is cultivated, and the protection that is provided to the soil in this regularly-tilled area is compromised.

Within the cultivated areas in all four dambos, the intensity scores have largely remained low and largely unchanged from 2008 to 2019, but with a small (13\%) increase in intensity in Mwansabamba (Supplementary Table S6). A slight improvement in Chiotha (Figure 2) is associated with a reduced 
proportional area under annual crops compared with sugarcane, which has a much lower frequency of tillage and provides better long-term cover to the soil.

\section{The soil organic matter component of dambo health}

Soil Organic Matter (SOM) makes a significant contribution to wetland functioning and productivity (e.g. by enhancing cation exchange capacity and soil water holding capacity), and can be profoundly affected by different land-use practices (Miller and Gardiner 1998). Several factors are likely to contribute to diminished SOM levels, including: (1) tillage of the soil, which occurs for preparing the beds and ridges, and for planting and weeding and which is high in all four dambos; (2) reduced cover of the soil, which occurs mainly when the ridges/beds are being prepared before the crops have developed good aerial cover; (3) combustion of the soil; (4) reduced level of wetness, exposing the soil to higher oxygen levels, and therefore more rapid decomposition rates; and (5) removal of plant material from the croplands. However, the returning of crop residues to the plots, which is widely practiced in all of the dambos, contributes positively to SOM, but this in itself is unlikely to counter all the aforementioned negative factors.

Considering the factors given above, the severity of SOM depletion in the currently cultivated plots is assigned the highest score in Mwansabamba (Z), followed by Chikakala (Z) and Katema (M) (Supplementary Table S7) owing mainly to the greatest reduction in wetness being at Mwansabamba and a high incidence of soil combustion at Mwansabamba and Chikakala. The impact in old abandoned plots is scored lower than in the currently cultivated areas given the absence of tillage, higher cover of the soil and cessation of soil burning. However, considering the fact that the recovery of SOM, even in wetlands, is generally slow (Six et al. 2002) it is assumed not to have fully recovered despite up to ten years of fallow. 
Comparing the 2008 and 2019 situation for each individual dambo, the intensity scores associated with cultivation have increased slightly in Mwansabamba (Z), owing primarily to the slight increase in level of artificial drainage, while in the other three they have declined slightly. In the case of Chiotha (M) this is associated with a reduced proportional area under annual crops compared with sugarcane, which has a much lower frequency of tillage, while in Chikakala $(Z)$ it is as a result of a slightly decreased level of artificial drainage.

\section{The nutrient cycling component of dambo health}

Impacts on nutrient cycling in the currently cultivated plots were assigned intensity based on the following key factors: (1) SOM: nutrient cycling is compromised by a decline in SOM (most severe in Mwansabamba (Z)), and consequent decline in cation exchange capacity (CEC), which affects the amount of nutrients potentially held in the soil (Miller and Gardiner 1998); (2) Cropping Intervals: in all four dambos, crops are predominantly annuals and the interruption of plant nutrient uptake between harvest of the first crop and growth of the following crop is frequent, thereby increasing risks of nutrient leaching, but interruption is less in Chiotha where there is more extensive sugarcane compared with annual crops; (3) Nutrient application: in all four dambos, the level of nutrient application is generally low to moderate, mainly as manure but also as inorganic fertilizer by some farmers, especially at Katema (M); and (4) Drainage: artificial drainage (most severe in Mwansabamba (Z) and least severe in Chiotha (M)) contributes to increased leaching of nutrients (Randall and Goss 2001).

Comparing 2008 with 2019 for each dambo, impact is slightly lower for Chikakala (Z) and slightly higher

for Mwansabamba (Z) (Figure 2), owing primarily to slight changes in SOM and the level of artificial drainage for 2008 compared with 2019. In Chiotha (M), the impact is slightly lower owing to less interruption of plant growth associated with a shift in cultivation to more sugar cane versus annual crops. Katema (M) remains very similar owing to similar cultivation practices and similar cultivation extent. 
Perennial vegetation rapidly establishes on abandoned plots, which contributes to the retention of nutrients, and probably also to the gradual recovery of nutrient levels. Based upon this consideration, and that erosion in the abandoned plots is very limited, impacts on nutrient cycling in the long-abandoned plots are assigned a low impact intensity score (Supplementary Table S8).

\section{The vegetation composition component of dambo health}

Vegetation structure has an important direct influence on hydrological flows and nutrient cycling, as dealt with in the hydrology and geomorphology components respectively. In addition, the plant species composition of the vegetation, as assessed in Figure 2, has an important influence over the condition of a wetland. Across all four dambos, in currently cultivated areas the natural vegetation has been completely removed, while in the recently abandoned areas ( $<2$ years since cultivation) recovery of vegetation species composition is still very limited. Therefore, together they are assigned close to the maximum impact intensity. In long-abandoned areas ( $>2$ years since cultivation) a much greater recovery of the natural vegetation was observed, varying from partial, where ruderal/pioneer species are generally still abundant, to fuller recovery where several of the original species have returned but still not fully attaining the composition of natural/uncultivated areas (Supplementary Table S9).

In both the 2008 and the 2019 assessments, vegetation was consistently the most impacted of the five components of ecological health across all of the dambos, which accords with the results of an ecological health assessment of East African wetlands by Beuel et al. (2016). Comparing the vegetation component score for each dambo in 2008 and 2019 (Figure 2) it can be seen that there was a general decline in scores for all dambos, but in Chiotha (M) it was extremely slight, more pronounced in Mwansabamba (Z) and intermediate in Chikakala (Z) and Katema (M). The changes seen in Figure 2 are primarily as a result of 
shifts in the extent of different land-cover types (notably a decline in natural vegetation and an increase in the areas of cleared and fallowed land) but the intensity scores within the respective land-uses largely remained unchanged. In addition, as noted by Kotze (2011) the vegetation in Chiotha dambo appears to recover its natural composition far more readily and quickly than Katema, and probably also the other two dambos. This may be owing to the inherently higher soil nutrient levels of the Chiotha dambo, which is naturally dominated by a few competitive species such as Echinochloa pyramidalis compared with the nutrient-poor and naturally more species-rich situation in the other three dambos (Kotze 2011).

\section{Overall dambo health summarized and sustainability of use assessed}

From the summary of overall ecological health given in Table 5 it can be seen that for Chikakala (Z) and Katema (M) there was only a slight decline in ecological health from 2008 to 2019 , in

Mwansabamba (Z) it was somewhat more, and in Chiotha (M) ecological health was fractionally improved. As reported previously for the five individual components of ecological health, the leading factor accounting for these differences was a shift in the extent of current cultivation in the wetland more so than altered practices within the cultivated areas.

By comparing the ecological health scores to the thresholds of potential concern in Table 5, it can be seen that they are largely above the thresholds. Therefore, utilization of the dambos is deemed to be largely sustainable. However, there are some important concerns, particularly with respect to the vegetation composition component, which is below the threshold for Katema (M) and Chiotha (M) dambos, primarily owing to the high extent of cultivation in these two dambos and the reduction in the areas of natural vegetation from which regeneration of cultivated sites can be supported. For the remainder of the ecological health components, the scores in all four wetlands are above the threshold for livelihood support but fall below that for managing catchment water quality (Table 5). The onerous threshold for 
catchment water quality used in Table 5 is arguably justified given that two of these wetlands are in the catchment of Lake Malawi, for which water quality impacts have been detected (Thieme et al. 2005).

As evident in Table 5, both Katema and Chiotha dambos (M) are below the generic threshold of concern for vegetation given in Kotze (2010), owing primarily to a fairly limited extent of remaining natural vegetation. This is of particular concern in the Katema dambo given the higher rate of decline in extent of natural area compared with Chiotha and the inherently slower rate of recovery of the vegetation in this (Katema) dambo referred to earlier. Katema had the smallest extent of natural vegetation out of the four wetlands, having dropped from 45\% in 2008 to 36\% in 2019 (Table 3). If the current trend continues then in the next 10 years the extent of natural vegetation may drop below $30 \%$, which is likely to pose a risk to the long-term viability of a diverse and viable pool of native species specifically adapted to the different ecological zones represented in the dambo. Although specific studies on dambos are lacking, one long-term study showed that conservation of grassland plant biodiversity contributed to primary productivity being more resilient to a major drought (Tilman and Downing 1994). Thus, the incremental depletion of the native vegetation pool in dambos such as Katema will potentially reduce the resilience of the dambo to extreme events, and will compromise the long-term sustainability of the use of this dambo.

In all four dambos, the ecological health category remained unchanged at B or C (small to moderately impacted) and the ecological health of the four dambos at the end of the SAB project has largely been sustained. In the case of Katema and Chiotha dambos (M), both still in category $\mathrm{C}$, this is owing primarily to the fact that both the extent and intensity of impact associated with cultivation in the dambo has remained very similar and with a small reduction in the percentage of the wetland cultivated. In addition, other impacts (e.g. from roads through the wetland and clearing of woodland in the wetland's catchment) were also similar in 2008 and 2019. Although the intensity of impact has increased only slightly in 
Mwansabamba (Z), the extent of cultivation has increased three-fold from 2008 to 2019. While this constitutes a major change, owing to the fact that the baseline extent in 2008 was very low (only $2 \%$ ), it does not constitute a major impact on wetland ecological health. Nevertheless, although its ecological health category remained at $\mathrm{B}$, the ecological health score declined noticeably more than for the other three dambos, and if the current rate of decline continues, over the next 10 years it will drop to a $\mathrm{C}$ category, which is the same as that of Katema and Chiotha. Chikakala $(Z)$ dambo had a very slow rate of decline in its ecological health and remained well inside category B. If current practices and rate of decline are sustained, Chikakala will only reach a C category after several decades.

This study confirmed that the key recommendations of the Striking a Balance (SAB) Project made in 2008 (Table 6), which are the cornerstones of the Functional Landscape Approach (FLA), are relevant today for maintaining the ecological health of dambos. The way in which this guidance has contributed to the ecological health scores for the diverse dambo types studied, provides further confirmation that the key recommendations of the (SAB) project and use of the FLA are likely to be applicable across a wide range of dambos with smallholder farmers, both in Malawi and Zambia, as well as more widely.

A review of the recommendations in Table 6 shows that they are largely being applied at the four dambos and that they seem to be generally well internalized amongst the dambo farmers involved in the 2019 discussion groups. However, they need to be transferred to new entrant dambo farmers. Applying these recommendations in the light of the institutional situation encountered suggests that communities need to consider how best through their existing Village Development Committees guidance can be agreed and sanctions enforced based on an enhanced understanding of the natural resource scenarios probable in specific wetlands. In addition, this study found that it would be useful to take note of six additions to the specific SAB guidelines (Table 7) which arise from this study so as to more effectively promote sustainable dambo cultivation in the long term through the FLA. These recommendations were prompted 
by the specific practices observed in the dambos that, according to the WET-SustainableUse assessment, were compromising sustainability of use, but which had not been not been explicitly covered in the FLA.

\section{Conclusions and recommendations}

Overall, the results of the study show that ecological health categories of the four dambos have largely been sustained under partial cultivation 10 years after the SAB project was completed, suggesting that dambo cultivation need not progress to cause serious degradation of these resources provided appropriate practices are followed. The livelihood benefits from this farming are considerable and these resources have an important role to play both in substantially addressing food security in the face of climate change and also in generating capital for enterprise diversification (Wood and McElwee, 2020). It is important, however, to acknowledge that in the context of the natural dynamics of a dambo, 10 years is not a long time, and a further monitoring of ecological health of the dambos in coming decades is recommended.

It is important to also acknowledge that the scope of this study only allowed for the assessment of four dambos, all of which were sites where the FLA had been promoted. For further investigations it is recommended that "control dambos", where the FLA has not been directly applied (but which are otherwise comparable to the four dambos), should also be included. In addition, the use of remote sensing with high-resolution, multi-spectral images is recommended to measure spatial metrics such as intactness of the dambo buffer and extent of cultivation in the dambo. Furthermore, it is recommended that the selected time-periods of assessment include both drought years and normal to above-average rainfall years. It is anticipated that such research would provide valuable insights into the multiple factors affecting dambo cultivation and the ecological health of the dambos and would contribute to 
understanding the relative importance of: (a) evolving market demand for wetland produce, (b) community coherence and the application of the FLA and associated by-laws, and (c) fluctuating climate in explaining the reduced pressure on the Malawi dambos for vegetable production observed in July 2019 (which followed a wet season with above-average rainfall).

The study contributes to evidence-based information on balancing food production and wetland ecosystem conditions, for which Wood and van Halsema (2008) identified an important need, and which may also potentially inform national and international policies promoting the sustainable use of wetlands. Specifically, the study has contributed to developing knowledge to assist with identifying the ecological bounds for wetland cultivation. Therefore, it can be seen as extending the work of the FAO Guidelines on Agriculture and Wetlands Interactions (Wood and van Halsema 2008) and contributing directly to addressing the need identified by Musasa and Marambanyika (2020) for more research on the environmental sustainability of dambo cultivation. Furthermore, the approach and method applied in the study could potentially contribute to informing the sustainable use interventions identified by Musasa and Marambanyika (2020) which are required to address the projected degradation of dambos.

The underlying approach of this study for the assessment of ecological health, namely that contained in WET-Health (Macfarlane et al. 2009), has already been successfully applied in an assessment of some Zimbabwe dambos by Marambanyika et al. (2016), and it is recommended that the method applied in this study has wider application in Africa for monitoring changes in ecological condition of dambos and identifying sustainability thresholds. Furthermore, it could be applied by government departments and NGOs operating with limited resources for carrying out assessments. Nevertheless, it is important to recognize that while the method can be applied rapidly, it relies predominantly on indirect proxies of ecological health rather than direct quantification of ecosystem attributes related to health, and therefore should be used as a supplement to detailed/high resolution assessments. In addition, it requires a 
reasonably high level of experience to apply, and training would be required to support its wider application.

\section{Acknowledgements}

Self Help Africa are gratefully acknowledged for funding this research. Orla Kilcullen of Self Help Africa, Dublin, Ireland, is thanked for her willingness and vision in supporting the study and her contribution to its overall administration. Albert Mate, Self Help Africa, Lusaka, Zambia and Peter Soko, Self Help Africa, Lilongwe, Malawi, Jonas Sampa, Wetland Action, Mpika, Zambia, and Patrick Thawe, Natural Resources Management Consultant, Lilongwe, Malawi, are thanked for facilitating the logistics of the field assessments and for liaison with local farmers, as well as for contributing valuable perspectives during the field assessments. Paul Wagstaff, Self Help Africa, Dublin, Ireland, is thanked for reviewing the initial sustainability assessment report of the four sites and contributing very valuable feedback. Above all, we would like to thank the members of the four communities who engaged in the field surveys and discussions. The authors would also like to acknowledge the very helpful comments from two reviewers of the first draft of this manuscript.

\section{Declarations}

Funding: Funding for this research was provided by Self Help Africa

Conflicts of interest/Competing interest: No conflicts of interest/competing interests are known.

Ethics approval: No ethics approval was required as the research was not involving humans and/or animals.

Consent to participate: No consent to participate were required as the research was not involving humans. Consent for publication: Consent for publication was obtained from the funding organization. 
Availability of data and material: The data for the assessment included in the study is given as supplementary material.

Code availability: Not applicable, as there was no software application or custom code development. Authors' contributions: DCK co-designed the research, collected the field data and led the writing of the manuscript, and APW co-designed the research, assisted with field data collection and writing of the manuscript.

\section{Figure and table captions}

Figure 1: Location of the four dambos selected for the study

Figure 2: The ecological health of the health of four dambos assessed in 2008 and 2019, with health represented on a scale of 0 (critical) to 10 (pristine) and the Threshold of Potential Concern (TPC) for Supporting Livelihoods shown as a dashed line: for the five components of health: (a) hydrology, (b) geomorphology, (c) Soil Organic Matter (SOM), (d) nutrient cycling, and (e) vegetation composition.

Table 1: Guideline for assessing the intensity of impact and ecological health of wetlands (modified from Macfarlane et al., 2009)

Table 2: Key biophysical features of the four dambos

Table 3: Approximate extent of different land-cover types in the four dambos (as a percentage of the dambo area)

Table 4: Approximate extent of different land-cover types in the upstream and adjacent catchments of the four dambos (as a percentage of the upstream catchment area) 
Table 5: Summary of the ecological health of the four dambos, assessed on a scale of 0 (critical) to 10 (pristine) and with the ecological health category represented on a scale of $\mathrm{F}$ (critical) to A (pristine)

Table 6: Key Recommendation of the Functional Landscape Approach from the Striking a Balance Project

Table 7: Additional Recommendations for the Functional Landscape Approach, based on 2019 Field Assessment

\section{References}

Acres B D, Rains A B, King R B, Lawton R M, Mitchell A J B, and Rackham L J (1985) African dambos: their distribution, characteristics and use. In: Thomas M F and Goudie A S (eds.) Dambos: small channelless valleys in the tropics. Zeitschrift für Geomorphologie, Supplement 52, 147-169

Beuel S, Alvarez M, Amler E, Behn K, Kotze D, Kreye C, Leemhuis C, Wagner K, Willy DK, Ziegler S, Becker M (2016) A rapid assessment of anthropogenic disturbances in East African wetlands. Ecological Indicators 67: 684-692.

Davidson NC (2014) How much wetland has the world lost? Long-term and recent trends in global wetland area. Marine and Freshwater Research 65:934-941. 
Dixon A, Carrie R (2015) Creating local institutional arrangements for sustainable wetland socioecological systems: lessons from the 'Striking a Balance' project in Malawi, International Journal of Sustainable Development \& World Ecology,DOI: 10.1080/13504509.2015.1107861

Dixon M, Loh JR, Davidson NC, Beltrame C, Freeman R, Walpole M (2016) Tracking global change in ecosystem area: the wetland extent trends index. Biological Conservation 193:27-35.

Finlayson CM, Davies GT, Moomaw WR, Chmura GL, Natali SM, Perry JE, Roulet N, Sutton-Grier A E (2019) The Second Warning to Humanity - Providing a Context for Wetland Management and Policy. Wetlands 39: 1-5.

Kotze DC (2009) An assessment of the ecological sustainability of the use of three dambos in the Mpika Distrcit, Zambia. Unpublished report submitted to Wetland Action and Wetland International, Wageningen, The Netherlands.

Kotze DC (2010) WET-SustainableUse: A system for assessing the sustainability of wetland use. WRC Report No. TT 438/09. Water Research Commission, Pretoria.

Kotze DC (2011) The application of a framework for assessing ecological condition and sustainability of use to three wetlands in Malawi. Wetlands Ecology and Management 19: 507-520.

Kotze DC (2013) Assessing the ecological sustainability of wetland cultivation: experiences from Malawi and Zambia. In: Wood A, Dixon A, and McCartney (eds.) Wetland management and sustainable livelihoods in Africa. Earthscan, London. 
Kotze DC, Walters DJ, Nxele IZ (2008) A baseline description of the ecological state and sustainability of use of three selected dambos in the Kasungu District, Malawi. Unpublished report submitted to Wetland Action and Wetland International, Wageningen, The Netherlands.

Macfarlane DM, Kotze DC, Ellery WN, Walters D, Koopman V, Goodman P, Goge M (2009) WETHealth: A technique for rapidly assessing wetland health. WRC Report No. TT 340/08. Water Research Commission, Pretoria.

Marambanyika T, Beckedahl H, Ngetar NS, Dube T (2016) Assessing the environmental sustainability of cultivation systems in wetlands using the WET-Health framework in Zimbabwe, Physical Geography, DOI: 10.1080/02723646.2016.1251751

Mbewe A (2007) Maintaining Seasonal Wetlands and their Livelihood Contributions in Central Southern Africa: PRA Report for Chimu Project Mpika District, Zambia. Unpublished report submitted to the Wetlands and Poverty Reduction Project of Wetlands International, Wageningen, The Netherlands.

Mbewe A, Sampa J (2018) Wider impacts of wetland innovation in northern Zambia. Unpublished research report.

McCartney MP, Masiyandima M, Houghton-Carr HA (2005) Working wetlands: classifying wetland potential for agriculture. Research Report 90. International Water Management Institute (IWMI), Colombo. 
McCartney MP, Neal C (1999) Water flow pathways and water balance within a headwater catchment containing a dambo: inferences drawn from hydrochemical investigations. Hydrology and Earth System Sciences 3, 581-91.

McElwee G, Wood A (2017) Wetland entrepreneurs: diversity in diversification in Zambian farming. Journal of Small Business and Enterprise Development. https://doiorg.libaccess.hud.ac.uk/10.1108/JSBED-03-2017-0089

Miller RW, Gardiner DT (1998) Soils in our environment, 8th edn. Prentice Hall, New Jersey.

Msukwa CAPS (2007) Baseline PRA Report for Wetland Demonstration Sites, Simlemba Sustainable Rural Livelihoods Project, Kasungu District, Malawi. Report submitted to the Wetlands and Poverty Reduction Project of Wetlands International, Wageningen, The Netherlands.

Musasa T, Marambanyika T (2020) Threats to sustainable utilization of wetland resources in ZIMBABWE: a review. Wetlands Ecol Manage 28:681-696

Ndiyoi M, Sampa J, Thawe P, Wood A (2009) Striking a balance: maintaining seasonal dambo wetlands in Malawi and Zambia. In: Mundy P. (ed.) Planting trees to eat fish. Field experiences in wetlands and poverty reduction. Wageningen, Wetlands International, pp. 27-39.

Nyamadzawo G, Wuta M, Nyamangara J, Nyamugafata P, Chirinda N (2015) Optimizing dambo (seasonal wetland) cultivation for climate change adaptation and sustainable crop production in the smallholder farming areas of Zimbabwe. Int J Agric Sust 13:23-39 
Nyirenda M A (2008) Biodiversity assessment report for three Mpika wetlands of SAB. Report submitted to Wetland Action.

Rebelo L-M, McCartney MP, Finlayson CM (2010) Wetlands of sub-Saharan Africa: distribution and contribution of agriculture to livelihoods. Wetlands Ecology and Management 18: 557-572.

Randall G W, and Goss M J (2001) Nitrate losses to surface water through subsurface, tile drainage. In: Follet R F, Hatfield J L (eds.) Nitrogen in the Environment: Sources, Problems, and Management. Elsevier.

Rogers KH, Biggs H (1999) Integrating indicators, endpoints and value systems in strategic management of the rivers of the Kruger National Park. Freshwater Biology 41: 439-451.

Sampa J (2008) Striking a Balance: Maintaining Seasonal Wetlands and their livelihood contributions in central southern Africa. Sustainable dambo cultivation. Report submitted to Wetland Action.

Six J, Feller C, Denef K, Ogle SM, de Moraes S, Albrecht A (2002) Soil organic matter, biota and aggregation in temperate and tropical soils - effects of no-tillage. Agronomie 22: 755-775

Strømgaard P (1984). Field studies of land use under chitemene shifting cultivation, Zambia. Geografisk Tidsskrift 84: 78-85. 
Thieme ML, Abell R, Staissny MLJ, Skelton P, Lehner B, Teugls GG, Toham AK, Burgse N, Olson D (2005) Freshwater ecoregions of Africa and Madagascar: a conservation assessment. Island Press, Washington, D C.

Tilman D, Downing J A (1994) Biodiversity and stability in grasslands. Nature 367: 363-365.

Trapnell C G, 1953. The soils, vegetation and agriculture of North-Eastern Rhodesia. Lusaka, Government Printer.

von der Heyden C J (2004) The hydrology and hydrogeology of dambos: a review. Progress in Physical Geography 28: 544-564.

Wood A (2008) Striking a Balance: maintaining seasonal wetlands \& their livelihood contributions in central Southern Africa. FINAL TECHNICAL REPORT. Unpublished report submitted by Wetland Action to Wetlands International, Wageningen, The Netherlands.

Wood A, McElwee G (2020) Innovation in Zambia's wetland farming as a stimulus to rural entrepreneurship. In: Dobson S. (ed.) Enterprising Africa. Routeledge, Abingdon.

Wood A P, van Halsema G E (2008) Scoping agriculture - wetland interactions: Towards a sustainable multiple-response strategy. FAO Water Reports, 33. FAO, Food and Agriculture Organization of the United Nations, Rome, Italy. 
Wood A, Thawe P (2013) Catchments and wetlands: a functional landscape approach to sustainable use of seasonal wetlands in central Malawi. In: Wood A, Dixon A, and McCartney (eds.) Wetland management and sustainable livelihoods in Africa. Earthscan, London. 


\section{Tables}

Table 1: Guideline for assessing the intensity of impact and ecological health of wetlands (modified from Macfarlane et al., 2009)

\begin{tabular}{|l|l|c|c|}
\hline $\begin{array}{l}\text { Impact intensity } \\
\text { category }\end{array}$ & $\begin{array}{l}\text { Impact score } \\
\text { range }\end{array}$ & Health score range & Health category \\
\hline None/ negligible & $0-0.9$ & $9.1-10$ & $\mathrm{~A}$ \\
\hline Small & $1-1.9$ & $8.1-9$ & $\mathrm{~B}$ \\
\hline Moderate & $2-3.9$ & $6.1-8$ & $\mathrm{C}$ \\
\hline Large & $4-5.9$ & $4.1-6$ & $\mathrm{D}$ \\
\hline Serious & $6-7.9$ & $2.1-4$ & $\mathrm{E}$ \\
\hline Critical & $8-10$ & $0-2$ & $\mathrm{~F}$ \\
\hline
\end{tabular}


Table 2: Key biophysical features of the four dambos

\begin{tabular}{|l|l|l|l|l|}
\hline Dambo name & $\begin{array}{l}\text { Dambo size } \\
\text { (ha) }\end{array}$ & $\begin{array}{l}\text { Size of the } \\
\text { dambo's } \\
\text { catchment (ha) }\end{array}$ & $\begin{array}{l}\text { Dambo area } \\
\text { as a of its } \\
\text { catchment }\end{array}$ & HGM (Hydrogeomorphic) setting of the dambo \\
\hline Katema & $33 \mathrm{ha}$ & 279 ha & $13 \%$ & $\begin{array}{l}\text { Lateral seepage grading gradually into a valley } \\
\text { bottom (predominantly unchanneled) located in } \\
\text { the headwater }\end{array}$ \\
\hline Chikakala & 254 ha & 1817 ha & $14 \%$ & $\begin{array}{l}\text { As above, but valley bottom predominantly } \\
\text { channeled }\end{array}$ \\
\hline Mwansabamba & $\begin{array}{l}369 \text { ha } \\
1292 \text { ha }^{1}\end{array}$ & 9130 ha & $\begin{array}{l}4 \% \\
14 \%\end{array}$ & $\begin{array}{l}\text { As above, but valley bottom located somewhat } \\
\text { downstream of the headwaters }\end{array}$ \\
\hline Chiotha & 17 ha & 808 ha & $2 \%$ & $\begin{array}{l}\text { Valley bottom, channeled in the uppermost and } \\
\text { lowermost portions but predominantly } \\
\text { unchanneled }\end{array}$ \\
\hline
\end{tabular}

${ }^{\text {aThe }} 369$ ha of assessed dambo combined with an additional 923 ha of dambo lying immediately upstream 
Table 3: Approximate extent of different land-cover types in the four dambos (as a percentage of the dambo area)

\begin{tabular}{|c|c|c|c|c|c|c|c|c|}
\hline \multirow[t]{2}{*}{ Land-use type } & \multicolumn{2}{|c|}{ Chikakala } & \multicolumn{2}{|c|}{ Mwansabamba } & \multicolumn{2}{|c|}{ Katema } & \multicolumn{2}{|c|}{ Chiotha } \\
\hline & 2008 & 2019 & 2008 & 2019 & 2008 & 2019 & 2008 & 2019 \\
\hline Currently cultivated & $2.0 \%$ & $3.0 \%$ & $2.0 \%$ & $6.0 \%$ & $29.0 \%$ & $26.0 \%$ & $23.0 \%$ & $22.0 \%$ \\
\hline Recently abandoned & $3.0 \%$ & $4.0 \%$ & $2.0 \%$ & $5.0 \%$ & $11.0 \%$ & $16.0 \%$ & $12.0 \%$ & $11.0 \%$ \\
\hline Old abandoned & $8.0 \%$ & $11.0 \%$ & $7.5 \%$ & $12.0 \%$ & $13.0 \%$ & $20.0 \%$ & $14.0 \%$ & $18.0 \%$ \\
\hline Natural/ near-natural & $87.0 \%$ & $82.0 \%$ & $88.0 \%$ & $76.0 \%$ & $45.0 \%$ & $36.0 \%$ & $42.0 \%$ & $40.0 \%$ \\
\hline Roads & & & $0.5 \%$ & $0.5 \%$ & & & & \\
\hline Road prep. & & & & $0.5 \%$ & & & & \\
\hline Erosion gullies & & & & & $0.1 \%^{a}$ & $0.1 \%^{a}$ & $9.0 \%$ & $9.0 \%$ \\
\hline Dam & & & & & $2.0 \%$ & $2.0 \%$ & & \\
\hline
\end{tabular}

${ }^{a}$ Very localized minor erosion associated with the spillway of the dam 
Table 4: Approximate extent of different land-cover types in the upstream and adjacent catchments of the four dambos (as a percentage of the upstream catchment area)

\begin{tabular}{|c|c|c|c|c|c|c|c|c|}
\hline \multirow[t]{2}{*}{ Landcover } & \multicolumn{2}{|c|}{ Chikakala } & \multicolumn{2}{|c|}{ Mwansabamba } & \multicolumn{2}{|c|}{ Katema } & \multicolumn{2}{|c|}{ Chiotha } \\
\hline & 2008 & 2019 & 2008 & 2019 & 2008 & 2019 & 2008 & 2019 \\
\hline "Permanent" cultivation areas ${ }^{\mathrm{a}}$ & $6.0 \%$ & $10.0 \%$ & $8.0 \%$ & $14.0 \%$ & $66.0 \%$ & $68.0 \%$ & $53.0 \%$ & $59.0 \%$ \\
\hline Chitemene cultivated areas $^{a}$ & $53.0 \%$ & $52.0 \%$ & $59.0 \%$ & $56.0 \%$ & $0.0 \%$ & $0.0 \%$ & $9.0 \%$ & $10.0 \%$ \\
\hline $\begin{array}{l}\text { Homesteads, roads, tracks and paths } \\
\& \text { other hardened bare areas }\end{array}$ & $1.0 \%$ & $1.5 \%$ & $2.0 \%$ & $3.0 \%$ & $8.0 \%$ & $9.0 \%$ & $8.0 \%$ & $9.0 \%$ \\
\hline $\begin{array}{l}\text { Eucalypts bananas and other } \\
\text { introduced trees }\end{array}$ & $1.0 \%$ & $1.5 \%$ & $1.0 \%$ & $2.0 \%$ & $2.0 \%$ & $3.0 \%$ & $2.0 \%$ & $3.0 \%$ \\
\hline Natural/ near-natural woodland & $39.0 \%$ & $35.0 \%$ & $30.0 \%$ & $25.0 \%$ & $24.0 \%$ & $20.0 \%$ & $28.0 \%$ & $19.0 \%$ \\
\hline $\begin{array}{l}\text { Buffer index, ranging from } * \text { (no } \\
\text { buffer) to } * * * * * \text { (complete and } \\
\text { extensive buffer) }\end{array}$ & $* * * *$ & $* * *$ & $* * * *$ & $* * *$ & $* * * *$ & $* * *$ & $* *$ & $* *$ \\
\hline
\end{tabular}

${ }^{a}$ Chitemene areas (includes infields, outfields and recovering areas) generally appear as light-coloured circular-shaped areas in the Google Earth image in an otherwise dark green woodland matrix. Lighter areas that are rectangular in shape, usually appearing brown in the Google Earth image, are assumed to generally be more permanently cultivated, and are referred to as "Permanent" cultivation areas. 
Table 5: Summary of the ecological health of the four dambos, assessed on a scale of 0 (critical) to 10 (pristine) and with the ecological health category represented on a scale of $F$ (critical) to A (pristine)

\begin{tabular}{|c|c|c|c|c|c|c|c|c|c|c|}
\hline \multirow[t]{2}{*}{$\begin{array}{l}\text { Components of } \\
\text { ecological health }\end{array}$} & \multicolumn{2}{|c|}{ Chikakala } & \multicolumn{2}{|c|}{$\begin{array}{l}\text { Mwansa- } \\
\text { bamba }\end{array}$} & \multicolumn{2}{|c|}{ Katema } & \multicolumn{2}{|c|}{ Chiotha } & \multicolumn{2}{|c|}{$\begin{array}{l}\text { Thresholds of } \\
\text { Potential } \\
\text { Concern }\end{array}$} \\
\hline & $\begin{array}{l}200 \\
8\end{array}$ & 2019 & 2008 & 2019 & 2008 & 2019 & 2008 & 2019 & $\mathrm{C}$ & $\mathbf{L}$ \\
\hline Hydrology & 8.79 & 8.53 & 8.66 & 7.94 & 6.95 & 6.63 & 6.77 & 6.52 & $<8$ & $<6$ \\
\hline $\begin{array}{l}\text { Sediment } \\
\text { accumulation/ erosion }\end{array}$ & 9.74 & 9.71 & 9.63 & 9.41 & 9.33 & 9.41 & 7.62 & 7.72 & $<8$ & $<7$ \\
\hline $\begin{array}{l}\text { Soil organic matter } \\
\text { accumulation }\end{array}$ & 8.70 & 8.62 & 8.70 & 8.28 & 7.32 & 7.30 & 7.30 & 7.56 & $<8$ & $<7$ \\
\hline Nutrient cycling & 9.65 & 9.55 & 9.64 & 9.20 & 8.22 & 8.22 & 7.91 & 8.08 & $<9$ & $<7$ \\
\hline Vegetation & 7.33 & 7.07 & 7.38 & 6.77 & 4.72 & 4.30 & 4.54 & 4.52 & $<5$ & $<5$ \\
\hline OVERALL & 8.84 & 8.68 & 8.79 & 8.28 & 7.27 & 7.12 & 6.82 & 6.85 & & \\
\hline $\begin{array}{l}\text { Ecological health } \\
\text { category }\end{array}$ & B & B & B & B & $\mathrm{C}$ & $\mathrm{C}$ & $\mathrm{C}$ & C & & \\
\hline
\end{tabular}

Threshold $\mathrm{C}=$ with the primary objective being management of catchment water quality

Threshold $\mathrm{L}=$ with the primary objective being management for sustaining local livelihoods 
Table 6: Key Recommendation of the Functional Landscape Approach from the Striking a Balance Project Confine cultivation in the dambo to mainly during the dry season Maintain the central areas of the dambo under natural vegetation Maintain extensive areas (preferably $>50 \%$ ) of the dambo under natural vegetation Maintain a buffer of natural vegetation around the dambo Practice crop rotation Limit cultivation of crops with high water demand, e.g. sugar cane Use manure/compost in preference to mineral fertilizer Include soil-building crops in the cultivated areas Avoid over-drainage

Prohibit eucalyptus trees in and near the dambo 
Table 7: Additional Recommendations for the Functional Landscape Approach, based on 2019 Field Assessment

Avoid burning of very organic rich soils

As far as possible reduce tillage of cultivated dambo plots, but recognizing the problems of applying minimum tillage in waterlogged soils

"Invest" in fallow areas to promote soil recovery, but recognizing that where the extent of dambo cultivation is high then opportunities for fallows will be very limited

Maintain a buffer of natural vegetation upstream of erosion features, such as headcuts

Avoid the use of biocides adjacent to streams and wells, especially ones used for domestic water

As far as possible use crop types and varieties with tolerance of waterlogging 


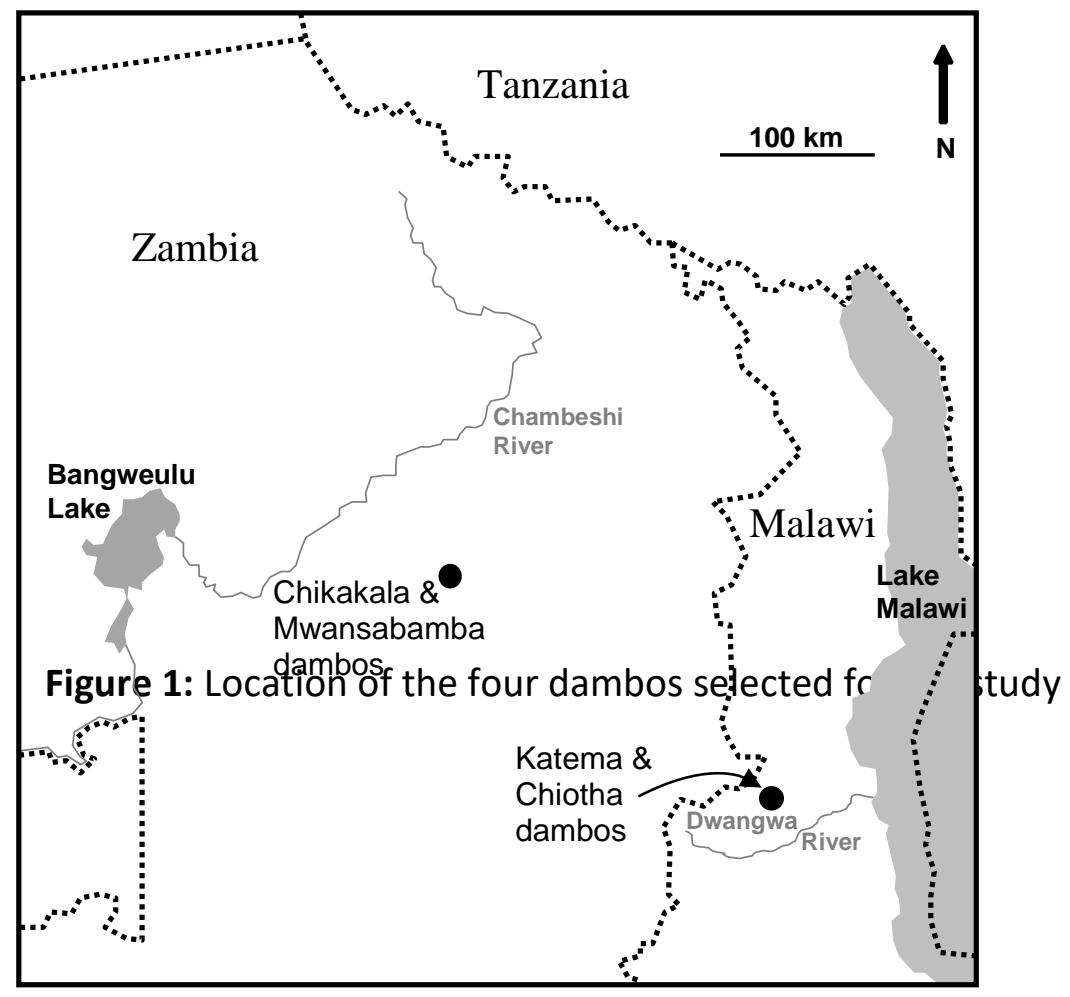



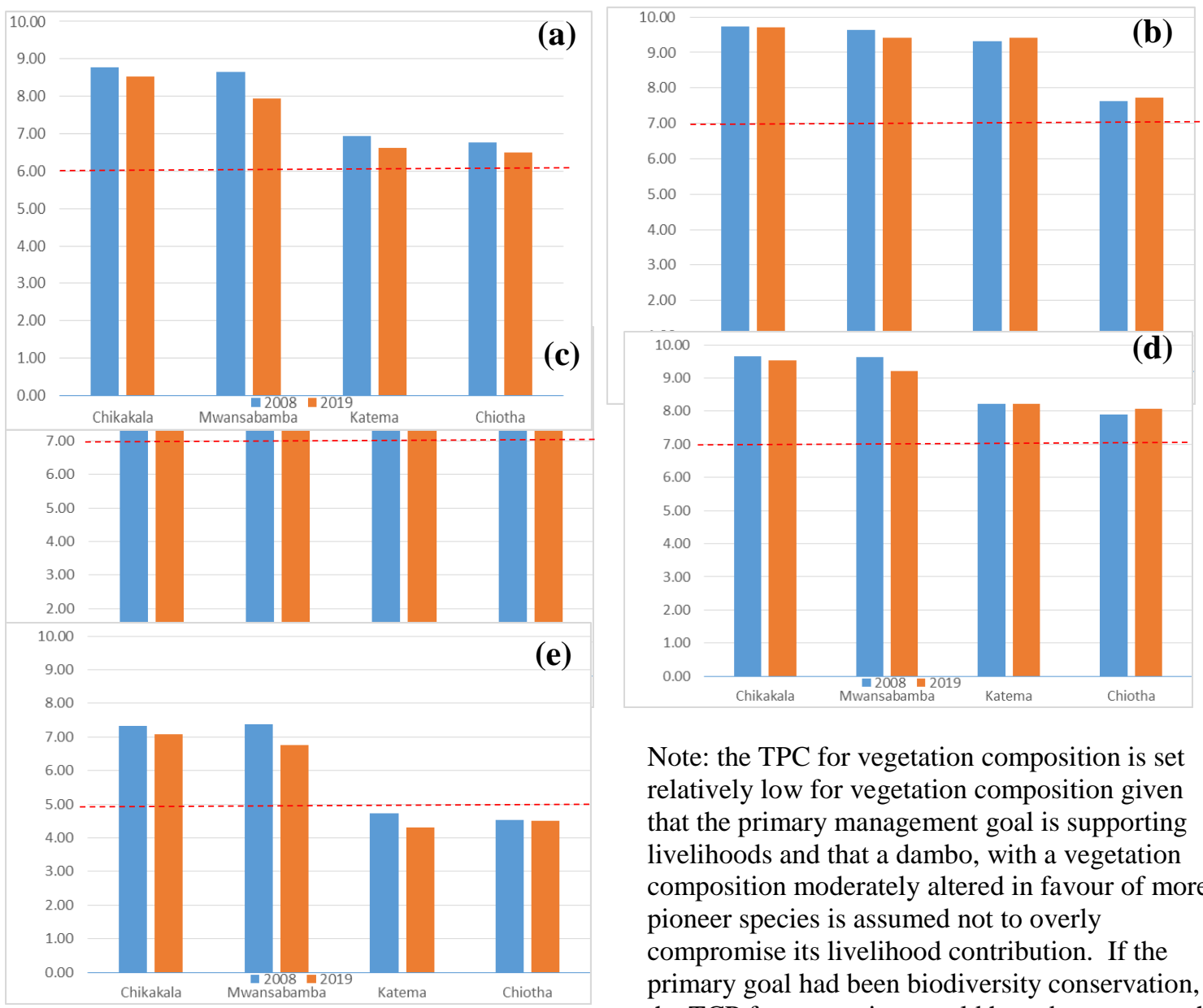

Note: the TPC for vegetation composition is set relatively low for vegetation composition given that the primary management goal is supporting livelihoods and that a dambo, with a vegetation composition moderately altered in favour of more pioneer species is assumed not to overly compromise its livelihood contribution. If the primary goal had been biodiversity conservation, the TCP for vegetation would have been set much higher.

Figure 2: The ecological health of the health of four dambos assessed in 2008 and 2019, with health represented on a scale of 0 (critical) to 10 (pristine) and the Threshold of Potential Concern (TPC) for Supporting Livelihoods shown as a dashed line: for the five components of health: (a) hydrology, (b) geomorphology, (c) Soil Organic Matter (SOM), (d) nutrient cycling, and (e) vegetation composition. 
